\title{
Paul Roell Medal Goes to India
}

In April 2014, the winners of the 2013 Zwick Science Award received their awards during the fifth Zwick Academia Day, held at the Universidad Rey Juan Carlos in Madrid. The specialist technical setting was provided by lectures on testing lightweight materials.

T

his year's winner of the Paul Roell medal, together with the first prize of $€ 5,000$, is Debrupa Lahiri of the Indian Institute of Technology in Roorkee. Debrupa Lahiri received her Master's Degree in Technology from the IIT Kanpur and her PhD from Florida International University. In her paper, she describes the bonding characteristics between carbon nanotubes and substrates. The findings can, for example, be applied to coating technologies for endoprostheses to enable better embedding of them in human tissue.

The second prize this year went to a paper from the United Kingdom, while two scientists, one from the USA and one from Germany, made an equally strong impression on the international jury, with the result that they shared third place.

The total of 119 entries for the Zwick Science Award, together with the series of scientific lectures during Academia Day, provide a comprehensive overview of important contemporary issues

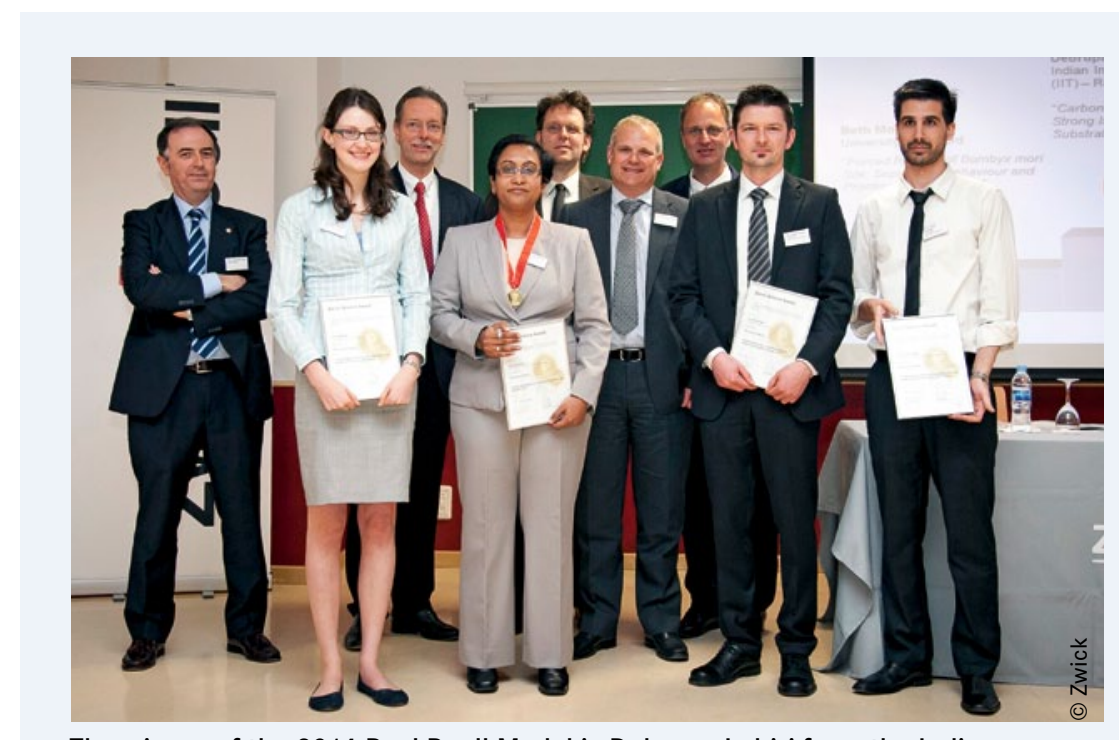

The winner of the 2014 Paul Roell Medal is Debrupa Lahiri from the Indian Institute of Technology in Roorkee.

in materials testing. In this way, Zwick is making an important contribution to the advancement of science.

Entries for the Zwick Science Award are invited once again this year. The closing date for submissions is the end of November 2014.

For further information, please visit: www.zwick.com/science-award

\section{BASF and Sinopec Build NPG Plant in China}

D emand for neopentylglycol (NPG) is growing, especially in the Asia Pacific region. To meet this demand, BASF and Sinopec are building a new world-scale production plant for NPG in China. The plant at the Verbund site, BASF-YPC Co., Ltd., a 50-50 joint venture in Nanjing, China, is planned to go on stream at the end of 2015 with a total annual capacity of about 40,000 metric tons. It will benefit from backward integration

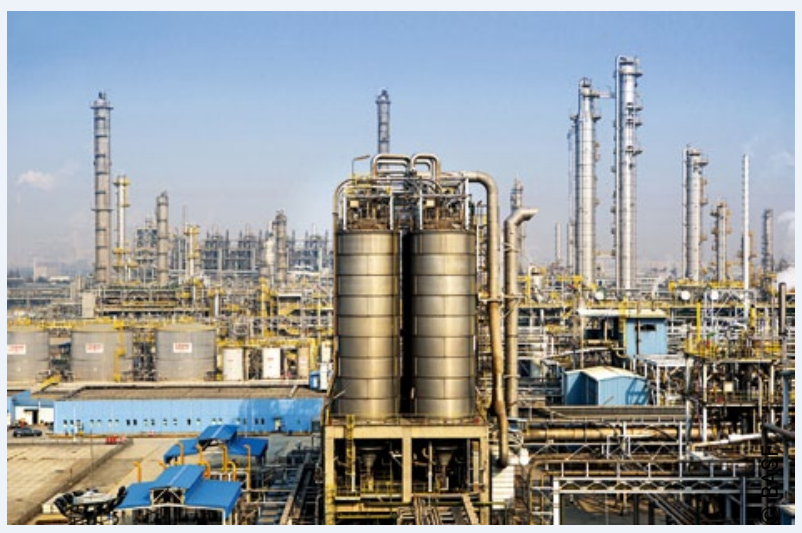

A new production plant for neopentylglycol (NPG) is being built in Nanjing. It will benefit from backward integration into the Nanjing Verbund site. into the Nanjing Verbund site. In addition to high delivery reliability, this will also maximise the efficient use of energy and resources.

NPG is a polyalcohol that is mainly used as a building block in polyester resins for coatings, unsaturated polyester and alkyd resins, lubricants and plasticizers. BASF already has NPG production facilities in Ludwigshafen, Freeport/USA and Jilin/ China. 